\section{Specificity of cue to consequence in aversion learning in the rat*}

\author{
MICHAEL DOMJAN and NANCY E. WILSON \\ McMaster University, Hamilton, Ont., Canada
}

Garcia \& Koelling (1966) showed that if rats are poisoned after ingesting a flavored solution in the presence of audiovisual cues, they will subsequently avoid only the taste stimulus, whereas if they are shocked, they learn to avoid only the audiovisual cues. The present experiments replicated these findings with one major change in experimental conditions: both taste and nongustatory CSs were presented in the absence of approach and ingestive behaviors to minimize involvement of ingestion in the associative process. (The taste CS was presented by flushing the oral cavity with a saccharin solution under conditions in which the rat would not drink.) Despite these changes, Garcia and Koelling's results were confirmed.

Rats poisoned after exposure to both taste and audiovisual stimulation are subsequently more likely to avoid the taste cue than the audiovisual stimulus. In contrast, rats receiving cutaneous shock after taste and a udiovisual stimulation are subsequently more likely to avoid the audiovisual cue than the taste cue (e.g., Garcia \& Koelling, 1966; Garcia, McGowan, Ervin, \& Koelling, 1968). This specificity of cue to consequence in aversion learning may reflect the evolution of a neuroanatomical separation between gustatory-visceral and telereceptor-cutaneous sensory systems (Garcia \& Ervin, 1968). Alternatively, the effect may result from differences in the way in which rats ordinarily receive gustatory and audiovisual stimulation. Novel gustatory cues are normally experienced only in conjunction with ingestion, whereas the reception of audiovisual stimulation often does not depend on a specific response by the organism.

Differences in the reception of gustatory and audiovisual stimulation were minimized in one experiment on the specificity of cue to consequence effect by presenting both types of cues contingent on approach and ingestive responses, the way novel taste cues are usually experienced (Garcia \& Koelling, 1966). Differences in the reception of gustatory and audiovisual cues may also be minimized by presenting both types of stimuli in the absence of approach and ingestive behaviors, the way audiovisual cues are often received. Gustatory stimuli can

*The research was supported by Grants APA-0298 (to S. Siegel) and APA-248 (to E. M. Stricker) from the National Research Council of Canada and Grant MA-3577 (to $S$. Siegel) from the Medical Research Council of Canada. The authors wish to thank Dr. Siegel for his considerable assistance with the manuscript. Requests for reprints should be sent to Michael Domjan. Department of Psychology, McMaster University, Hamilton, Ont., Canada. be presented in the absence of approach and ingestion by using a cannula that permits infusion of flavored solutions directly into the oral cavity. In preliminary work with 13 rats we found that none of the Ss ingested any of the flavored solution if it was infused very rapidly $(1 \mathrm{ml} / \mathrm{sec})$ while the Ss were water satiated.

\section{EXPERIMENT 1}

The specificity of cue to consequence effect was investigated, with a saccharin solution serving as the gustatory CS and a buzzer serving as the peripheral CS. Both CSs were presented in the absence of approach and ingestive behaviors, the saccharin solution being rapidly infused into the oral cavity of nonwater-deprived rats. (1966), the taste and nongustatory CSs had equal opportunity for conditioning, since they were presented simultaneously during training, and independent groups had this compound stimulus followed by either shock or toxicosis.

Subjects and Preexperimental Preparation

The Ss were 18 male Sprague-Dawley rats (Holtzman Co., Madison, Wis.), weighing 250 to $300 \mathrm{~g}$ and housed individually with food always available. Each $\mathrm{S}$ was implanted with an oral cannula consisting of a small-diameter polyethylene tube (Clay-Adams, "intramedic," P.E. 205) passed under the skin, with one end exiting at the back of the neck and the other entering the oral cavity at the right side just anterior to the molar teeth. The two ends were flared and held in place by polyethylene washers. In addition, the oral end was secured by a thin wire attached to the cannula and looped around subcutaneous tissue in the cheek. Each S also had a safety pin implanted in the skin of the back to serve as one of the poles for contact with the shock source.

Starting 4 days after cannulation, access to water was limited to $35 \mathrm{~min} /$ day. As in the study by Garcia \& Koelling
Adaptation

Three days of adaptation began after 4 days on the water-deprivation schedule. Each $\mathrm{S}$ had $35 \mathrm{ml}$ of water infused daily into the oral cavity via the cannula at $1 \mathrm{ml} / \mathrm{sec}$, followed by $10 \mathrm{~m}$ of water infused at $2 \mathrm{ml} / \mathrm{sec}$. The infusions were carried out after Ss had been allowed their daily access to water for $35 \mathrm{~min}$. Of this $35 \mathrm{~min}$ access to water, the first $15 \mathrm{~min}$ were provided during the last 2 days of adaptation by placing $S s$ in a test chamber with two drinking tubes filled with water.

\section{Conditioning}

Each of the three daily conditioning trials was conducted after Ss had been watered for $35 \mathrm{~min}$ in the home cage. The auditory CS was provided by an irregularly pulsed buzzer (mean = 4.6 times/sec) which added $20 \mathrm{~dB}$ to the 50-dB (SPD) background noise. The gustatory CS was provided by the oral infusion of a $0.2 \%$ sodium saccharin solution ( $w / v$ in tap water) at $1 \mathrm{ml} / \mathrm{sec}$. The two CSs were presented simultaneously for $35 \mathrm{sec}$, the taste CS being terminated by the oral infusion of $10 \mathrm{ml}$ of water at $2 \mathrm{ml} / \mathrm{sec}$. Immediately after presentation of the CSs, one group $(\mathrm{N}=6)$ was injected intraperitoneally with $4 \mathrm{ml}$ of $0.12 \mathrm{M}$ lithium chloride, a toxin. Another group $(\mathrm{N}=6)$ was shocked for $0.5 \mathrm{sec}$ and then injected with $4 \mathrm{ml}$ of isotonic saline (sodium chloride), while the remaining six Ss served as a control group and were only injected with isotonic saline. The shock (140 V ac) was administered by attaching one pole of the source to the metal conditioning chamber and the other to the safety pin implanted in the dorsal skin of each $\mathrm{S}$.

Testing

Starting the day after the last conditioning trial, two daily $15-\mathrm{min}$ preference tests were conducted, each followed by $20 \mathrm{~min}$ of water in the home cage. The test chamber had two drinking tubes. For saccharin preference tests, one tube was filled with saccharin and the other with tap water. For buzzer preference tests, both drinking tubes were filled with tap water and the buzzer was activated by licks from one of the two tubes. Ss were tested once with each CS, the order of these tests counterbalanced in each group. Preference was measured as the percentage of total fluid consumption consisting of the CS solution. All two-group comparisons were made with the Mann-Whitney U test (two-tailed).

Results and Discussion

Only Ss conditioned with lithium toxicosis learned to avoid the saccharin flavor. Figure $1 \mathrm{~A}$ shows that the saccharin preferences of lithium-injected Ss were lower than those of both saline-injected and 


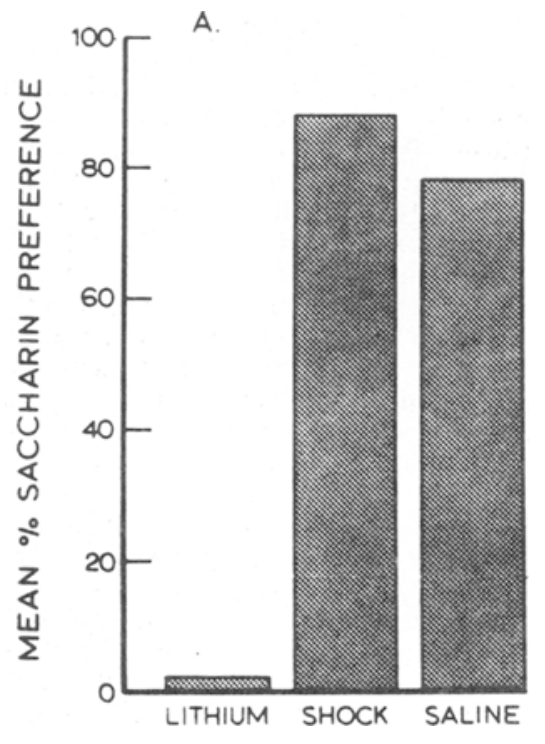

\section{US EMPLOYED}

Fig. 1. Saccharin and buzzer-water preferences of Ss exposed to both saccharin and the buzzer in conditioning with lithium, shock, or saline. shocked groups (ps $<.01$ ), which did not differ from each other $(p>.40)$. In contrast, only Ss conditioned with shock learned to avoid the buzzer. Figure 1B shows that the buzzer-water preferences of shocked Ss were lower than those of both the lithium- and saline-injected groups (ps<.01), which did not differ from each other results of Garcia \& Koelling (1966), with toxicosis but not shock, whereas the buzzer became associated with shock but not toxicosis.

These results confirm that the specificity of cue to consequence effect in aversion learning is independent of the method used to present the two CSs (Garcia \& Koelling, 1966) and extend this finding to a situation in which both taste and nongustatory cues are presented in the absence of approach and ingestive behaviors.

EXPERIMENT 2

Experiment 1 as well as the study by Garcia \& Koelling (1966) involved the simultaneous presentation of gustatory and auditory CSs during conditioning. In a recent experiment on aversion learning in quail, the specificity of cue to consequence effect observed was considerably attenuated when, during conditioning, the taste and nongustatory CSs were presented individually, using independent groups of Ss, rather than as a compound (Wilcoxon, Dragoin, \& Kral, 1971). Since a similar attenuation of the specificity of cue to consequence effect might occur in rat aversion learning, Experiment 2 was $(p>.40)$. Thus, as expected from the the saccharin flavor became associated

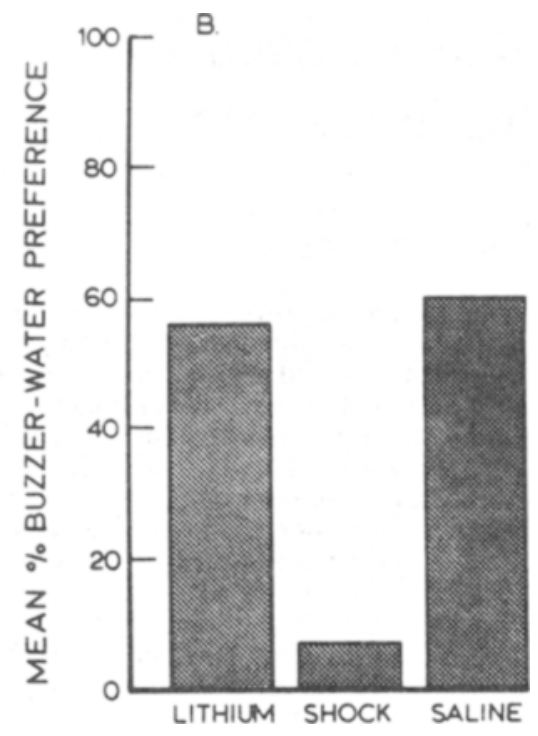

served as the CS for the remaining three groups. Under each CS condition, one group was injected with lithium chloride during conditioning, another group was shocked and injected with isotonic saline (sodium chloride), while the third group served as a control condition for the first two and only received the isotonic saline injections. Originally five Ss were assigned to each group; however, two Ss died before the end of the condition and the other in the buzzer-shock condition. tested with both the buzzer and the saccharin flavor. In order to allow comparison of the test results of Experiments 1 and 2, Ss in Experiment 2 were equated for pretest contact with the two stimuli by being exposed to the cue absent during conditioning 1.5 to $2.5 \mathrm{~h}$ after each conditioning trial. (Ss in Experiment 1 had been equated for pretest contact with the two stimuli by being exposed to both during conditioning.)

Results and Discussion

The pattern of results obtained was designed to replicate the results of Experiment 1 with individual presentation of taste and auditory CSs during conditioning.

\section{Method}

Experiment 2 was identical to Experiment 1 in all unspecified details. Thirty rats were used, each assigned to one of six independent groups. The buzzer served as the CS for three groups, while the taste of saccharin

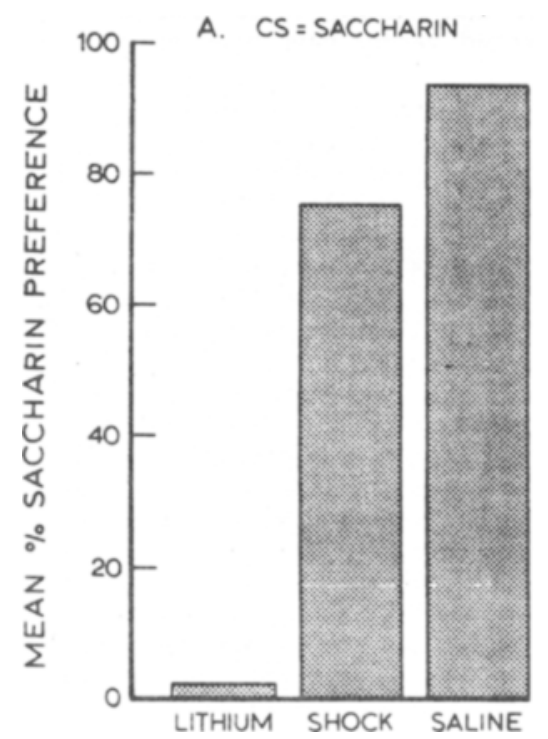
identical to that of Experiment 1 . Figure 2A shows that the saccharin flavor readily became associated with lithium toxicosis $(p<.01$ for comparison with saline treatment), whereas shock had no discernible effect ( $p>.50$ for comparison with saline treatment). In contrast, the buzzer readily became associated with shock ( $p<.05$ for comparison with experiment, one in the buzzer-lithium

As in Experiment 1, each $\mathrm{S}$ was

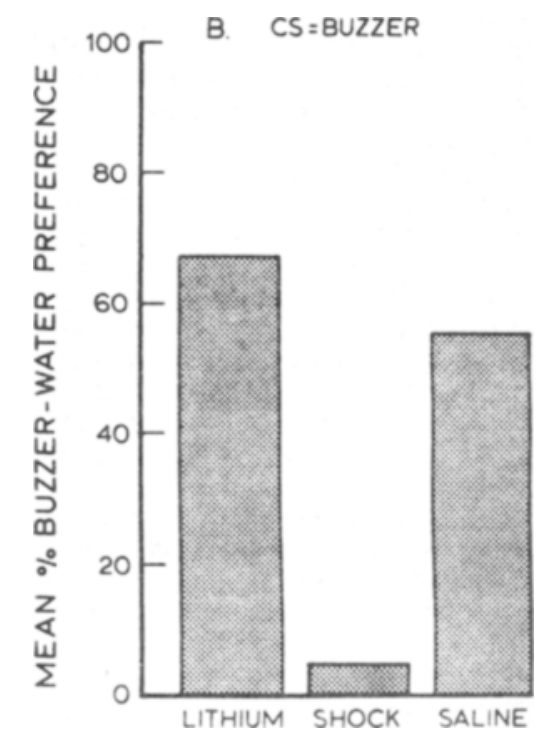

US EMPLOYED

Fig. 2. (A) Saccharin preferences of Ss exposed to saccharin in conditioning with lithium, shock, or saline. (B) Buzzer-water preferences of Ss exposed to the buzzer in conditioning with lithium, shock, or saline. 
saline treatment), whereas lithium toxicosis had no discernible effect ( $p>.50$ for comparison with saline treatment). (The three groups conditioned with the buzzer did not differ in preference for the saccharin flavor, and the three groups conditioned with saccharin did not differ in preference for the buzzer.)

The results of Experiment 2 confirm that the specificity of cue to consequence effect in rat aversion learning does not depend on the simultaneous presentation of taste and nongustatory cues during conditioning (Garcia, McGowan, Ervin, \& Koelling, 1968) and extend this finding to a situation in which both taste and nongustatory CSs are presented in the absence of ingestive behaviors.

GARCIA, J. \& ERVIN, F. R Gus t a tor $-v$ is ceral and telereceptor-cutaneous conditioning: Adaptation in internal and external milieus. Communications in Behavioral Biology, 1968, 1(Part A), 389-415.
GARCIA, J. \& KOELLING, R. A. Relation of cue to consequence in avoidance learning. Psychonomic Science, 1966, 4, 123-124.

GARCIA, J., McGOWAN, B. K., ERVIN, F. R.. \& KÖLLING, R. A. Cues: Their relative effectiveness as a function of the reinforcer. Science, 1968, 160 , 794-795.

WILCOXON, H. C., DRAGOIN, W. B., \& $K R A L, P$. A. Illness-induced aversions in rat and quail: Relative salience of visual and gustatory cues. Science, 1971, 171 . 826-828. 